\title{
Fotografía y propaganda. Misa en Dos Hermanas (Sevilla) durante la Guerra Civil española
}

\author{
José Manuel Baena Gallé \\ Consejería de Educación. Junta de Andalucía \\ baenagalle@gmail.com
}

El uso de las imágenes públicas siempre se ha asociado por el poder a la propaganda y al control de la población. Desde la Historia del Arte es posible analizar y explicar la importancia que tiene una imagen no solo desde su valor estético sino también por su significación ya que a través de ellas se pretende que el espectador visualmente sea capaz de comprender y asumir unos mensajes tanto políticos, como religiosos o ideológicos. En ese sentido, se muestran dos fotografías de actos celebrados en Dos Hermanas (Sevilla) durante la Guerra Civil Española por tropas italianas. La ciudad tenía según el censo de 1930 unos 15.000 habitantes y estaba comenzando un incipiente proceso de transformación industrial relacionado con la aceituna de mesa y los hilados de yute. Durante la guerra no hubo actividad bélica en la población salvo algunos controles y el incendio de la iglesia de Santa María Magdalena que el 20 de julio quedó en poder de las tropas alzadas e iniciándose un proceso represivo. Uno de los hitos más importantes fue la llegada de las tropas italianas a fines de 1936 o enero de 1937. Se acantonaron unos 1.000 soldados con una base logística y un retén. La oficialidad se alojaba en una fonda y en domicilios particulares, pero el centro de actuación de la unidad era el almacén de aceitunas «Los Lobillos» ubicado en la salida de Alcalá de Guadaíra (actual avenida 28 de Febrero), un lugar idóneo por el espacio que ofrecía y por estar próximo a una cantera, utilizada para prácticas de tiro y diversos entrenamientos. En junio de 1939 abandonaron Dos Hermanas en ferrocarril con destino a Cádiz donde serían embarcados (Hidalgo, 2014: 95-101).

La primera imagen muestra una misa de campaña en «Los Lobillos» ya publicada por su propietario José María Gó- mez Sánchez en un libro titulado El Paraíso abatido donde narra de forma novelada las vivencias de la población durante el inicio de la guerra (2014: 239 y contraportada) [1]. Además, existe una referencia a esta fotografía donde se la califica de «impresionante foto» (Hidalgo, 2014: 97)'. Se observa la fachada principal del almacén de aceitunas, de color blanco y con tejado a dos aguas, identificado por un rótulo en el que de forma parcial aparece la inscripción «...ITUNAS / C. ${ }^{\text {NA } L .}{ }^{. D A}$ ». En esta fachada, que en su parte superior aparece recorrida por postes de electricidad y cables, se ha dispuesto un escenario para la celebración de una misa de campaña. Sobre una estructura de madera para darle altura, probablemente un cajón o contenedor de mercancías militares, se ha situado una mesa de altar convenientemente vestida donde se encuentran los misales para la celebración y un centro de plantas a cada lado. Flanquean la mesa dos ametralladoras sobre sus trípodes y delante de ella y de espaldas al espectador se encuentra el sacerdote oficiante revestido de sagrado, colocado sobre otro cajón cubierto de tela, lo que le confiere una disposición preeminente en la escena. La mesa se cubre con un mantel blanco que deja una parte sin cubrir, lo que habla de que en parte del cajón antes aludido se ha establecido algún elemento, un panel o tablero, para potenciar la altura. La parte sin cubrir serviría para colocar la credencia, las vinajeras y el aguamanil necesarios para la ceremonia.

A la derecha de este conjunto se encuentra un soldado italiano descubierto, con la cabeza inclinada, que hace las veces de monaguillo. En línea con las ametralladoras se colocan sendas filas de soldados italianos armados y cubiertos por casco. Probablemente el momento concreto de la misa

Cómo citar este artículo: BAENA GALLÉ, José Manuel, "Fotografía y propaganda. Misa en Dos Hermanas (Sevilla) durante la Guerra Civil española», Boletín de Arte-UMA, n. ${ }^{\circ}$ 42, Departamento de Historia del Arte, Universidad de Málaga, 2021, pp. 259-262, ISSN: 0211-8483, e-ISSN: 2695-415X, DOI: http://dx.doi.org/10.24310/BoLArte.2021. vi42.11345 


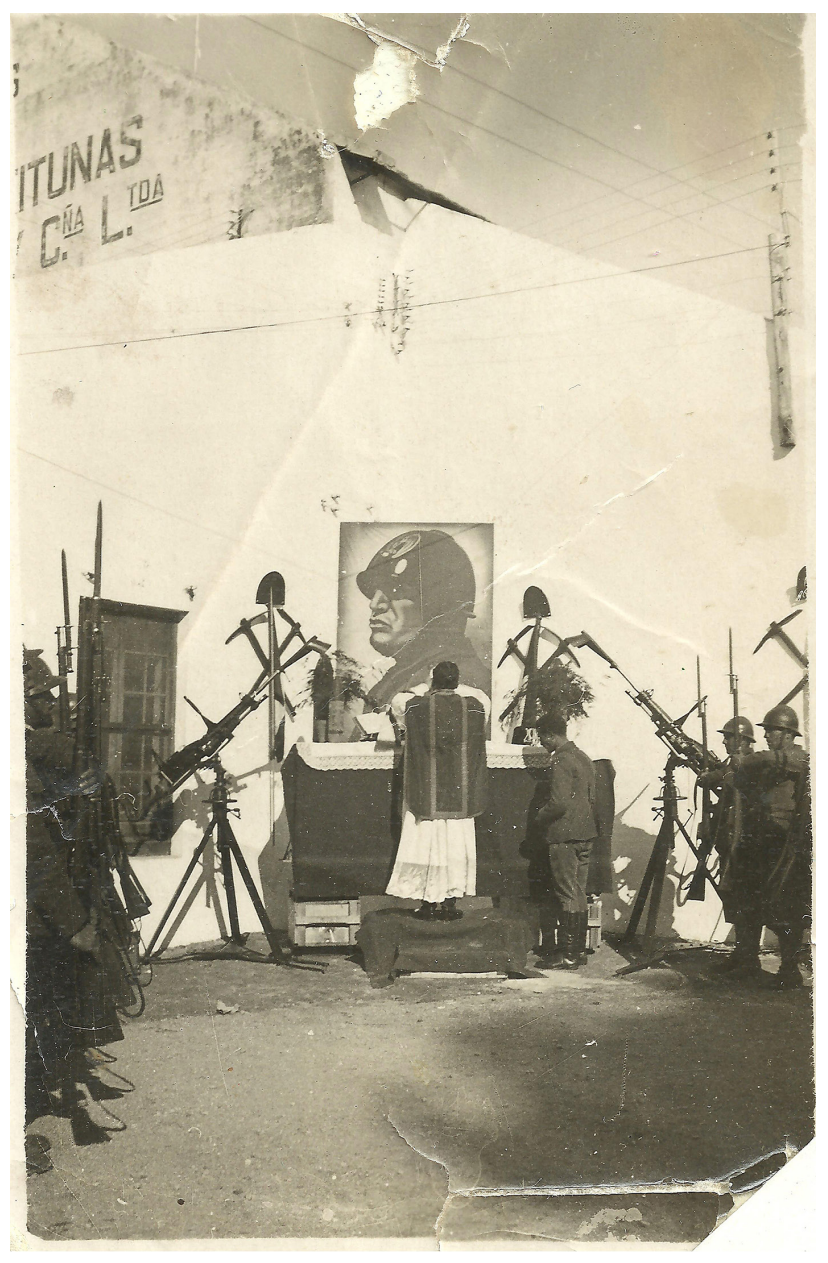

1. Misa de campaña («Los Lobillos», Dos Hermanas, Sevilla). Autor desconocido. Propiedad de José María Gómez Sánchez

sea la consagración ya que el sacerdote se encuentra con las manos unidas alzadas portando lo que parece la hostia consagrada y los soldados aparecen en posición de firmes presentando armas con sus fusiles y con la bayoneta calada. A la izquierda del oficiante se encuentra una ventana con la clásica reja de las construcciones andaluzas populares.

Sin embargo, el aspecto más sorprendente de esta escena es que la imagen que aparentemente preside la ceremonia religiosa en el altar es un cartel de gran tamaño que presenta un busto de Benito Mussolini con uniforme militar, la cabeza alzada y con casco. Ante este tipo de imágenes Scurati ha afirmado que el dictador fue el primer político que puso «el cuerpo en el centro de la comunicación política» lo que hacía que su popularidad fuese creciente (Verdú, 2020:
47). Flanqueando esta imagen se sitúan en la pared dos conjuntos decorativos formados por una pala cruzada por dos picos. Al observar la fotografía la única referencia religiosa que puede verse en realidad es la del propio sacerdote.

Para explicar esta disposición hay que recurrir a otra fotografía ya publicada donde se observa a un grupo de soldados delante de la fachada del almacén de aceitunas y del retrato de Mussolini (Gómez, 2014: 241; Hidalgo, 2014: 96) [2]. La tropa posa de manera informal en diferentes posturas y lleva sus uniformes, cascos y armas en un retrato de recuerdo y de camaradería, acompañados por civiles y algún niño. Lo más interesante es la disposición de la decoración de la fachada del almacén del que se tiene una imagen más amplia que en la primera fotografía. El retrato de Mussolini se encuentra a una altura entre 1,5 y 2 metros y está flanqueado por el conjunto de herramientas antes aludido, pero además a la derecha existe otro aparato similar y a la izquierda, pasada la ventana, otro. Todos estos elementos están colocados de forma regular y a una distancia similar. En la organización decorativa del muro existe orden y pulcritud lo cual podía ser debido a que éste debía ser el alojamiento definitivo de la unidad y el acuartelamiento donde tenían que permanecer durante toda la guerra. Incluso la estructura de pala y picos cruzadas podría hacer referencia a la especialidad militar de los soldados italianos, tal vez del arma de ingenieros o zapadores. En ese sentido Gómez señala que «Son dos mil soldados "voluntarios" con equipos y uniformes de artificieros» (2014: 238). Ambas imágenes, tal vez debido a su calidad, confunden la percepción del edificio ya que no se ve claramente cuál es su disposición. Al parecer, la fachada principal del almacén presenta dos naves añadidas, una al frente y otra en el lateral, lo cual puede ser observado en las cubiertas que se ven en la segunda fotografía. Esta disposición haría que entre el retrato de Mussolini y la ventana existiese una esquina lo que conformaría un pequeño rincón que es donde se celebra la ceremonia.

Ya Touchard señaló la importancia de la religión en los totalitarismos europeos de los años 30 del siglo XX fundamentalmente el fascismo y el franquismo (1985: 616). Según la liturgia católica la misa necesita de unas condiciones específicas de dignidad y presentación para realizarse. El derecho canónico dispone lo necesario sobre el lugar de celebración, vestimenta del oficiante o los diversos objetos necesarios para la celebración. No obstante, también se reguló 


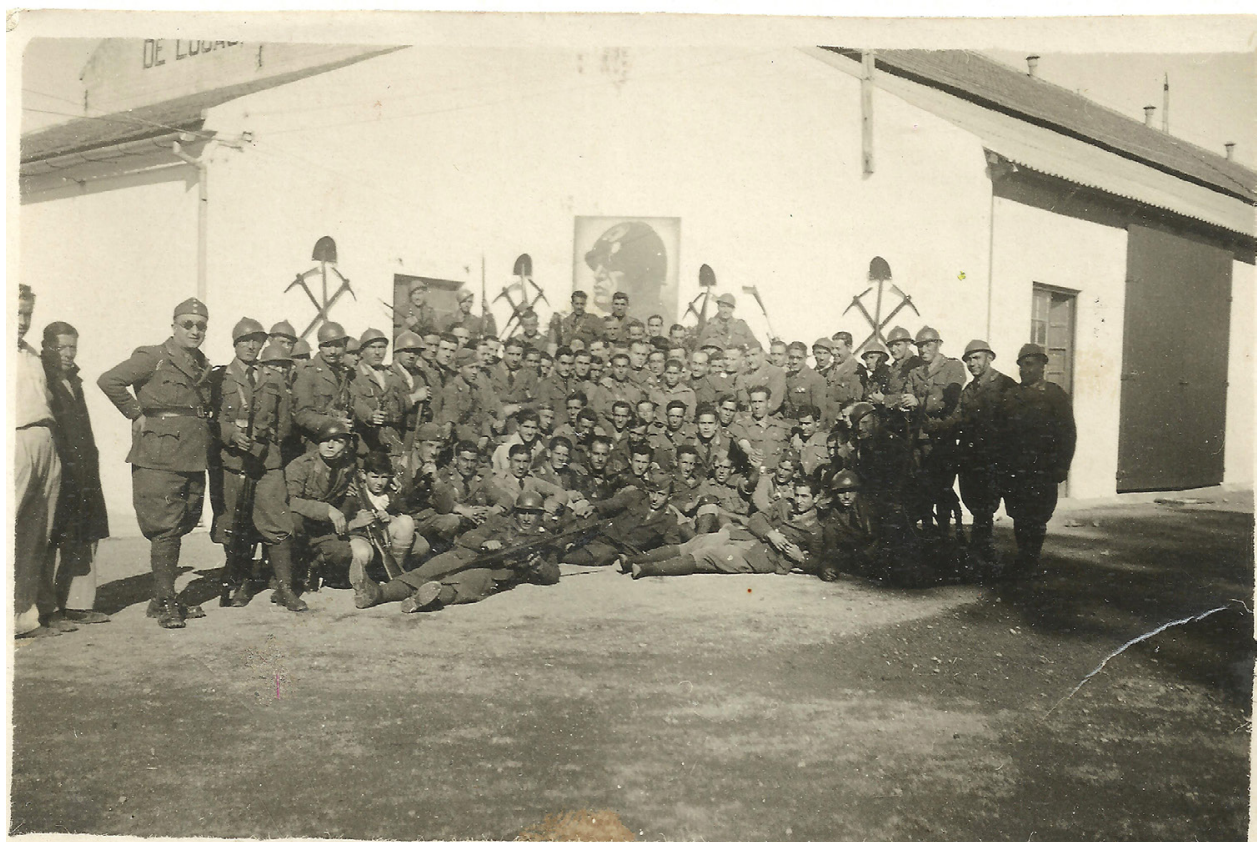

2. Grupo de soldados italianos y civiles («Los Lobillos», Dos Hermanas, Sevilla). Autor desconocido. Propiedad de José María Gómez Sánchez

la celebración de la misa en unas circunstancias concretas aunque debían estar justificadas y era necesario mantener unas meticulosas condiciones en la celebración del culto. El Código de Derecho Canónico de 1917 establecía la necesidad del uso de un altar portátil (o piedra consagrada) con sus ornamentos, las vestimentas del sacerdote y la existencia de un lugar decoroso. Todo altar debía tener unos accesorios, manteles y corporales, la cruz, los candeleros con las velas y como elementos secundarios las flores, sacras y atril (Righetti, 1955: 485). No obstante, en este caso sólo se observa que están presentes algunos de ellos. Al analizar la fotografía de la misa parece que los elementos litúrgicos son correctos, al menos, la mesa de altar vestida, con sus libros y decoración vegetal y las vestimentas del sacerdote. Se ignora si existe algún objeto litúrgico más ya que el oficiante oculta con su cuerpo la parte central de la mesa. Que el sacerdote aparezca de espaldas no debe sorprender ya que es un acto religioso anterior al Concilio de Vaticano II. Incluso la decoración con elementos bélicos puede ser considerada normal en un acto de carácter castrense como el presente.

Lo que sí llama la atención, como ha sido ya señalado, es el dominio de la escena por la imagen de Mussolini.
Es cierto que la segunda de las fotografías explica el porqué de la existencia de este retrato. La imagen ya existía previamente en el muro del almacén junto con los elementos decorativos de herramientas y tendrían un carácter casi permanente en la ornamentación del acuartelamiento siendo probablemente el frente de una especie de plaza de armas. La cuestión primordial es preguntarse qué hizo que se decidiese el montaje necesario para la celebración de la misa en ese punto específico. Es evidente que era el lugar más digno y más representativo del acuartelamiento italiano, de lo cual puede ser prueba el hecho de que la tropa para una foto informal eligiese el mismo sitio. Es posible que en el almacén-cuartel existiese otro espacio que permitiese la celebración de la misa pero quizás no tan icónico e importante para sus protagonistas y por eso se elige el lugar del retrato. No se debe poner en duda que la presidencia del acto religioso sería alguna imagen religiosa, un crucifijo de mesa casi con toda seguridad, pero sí parece que es el Duce, en un claro ejemplo de la importancia que tiene la imagen pública en el fascismo, el encargado de crear un efecto especial en los espectadores y seguidores del acto. Touchard ha señalado la importancia del «Jefe Carismático» para los mo- 
vimientos fascistas en los que era el elemento esencial de configuración ideológica afirmando que «el fascismo, antes que una política, es una mitología. Más que proponer un programa, impone un estilo. Tiene el sentido de la decoración, de la multitud, de la escenificación, de los grandes símbolos» (1985: 611). Todo ello es un instrumento para fortalecer la imagen del jefe y el liderazgo supremo del movimiento, o como afirma Touchard «entre el jefe y su pueblo se establece una comunicación de la que hasta entonces ningún régimen político había ofrecido equivalente» (1985: 612).

Benjamin ya señaló en 1936 que «la consecuencia lógica del fascismo es una estetización de la vida política» (2012: 58). Y aunque estas ideas pueden ser aplicadas a todos los totalitarismos de aquel momento, en este caso concreto lleva a suponer que la decisión de ubicar la mesa de altar bajo el retrato de Mussolini no debió ser responsabilidad ni del sacerdote ni, incluso, de los militares italianos. Simplemente era la situación lógica y asumida por todos: el acto público debía realizarse en el lugar más privilegiado del acuartelamiento que no podía ser otro que bajo la mirada del líder. Puede ser un acto más de utilización de elementos de propaganda para, en este caso, fortalecer a unos combatientes teóricamente ya muy ideologizados. Es una pequeña emulación de los grandes actos públicos del fascismo donde ejército, partido y líder se fusionaban con la multitud y en muchas ocasiones con intervención de la Iglesia católica.

La propia fotografía es muestra de un afán de trascendencia y de recordatorio del acto que, con todas las distancias necesarias, recuerda en su finalidad a las pinturas y grabados que en tiempos anteriores relataban las diferentes celebraciones públicas. También aporta un elemento de popularización -casi cualquier persona con los elementos técnicos necesarios podría hacerlo- y de posibilidad de captar el momento preciso y no una recreación posterior. Ya ha sido señalado que con la fotografía por primera vez lo importante no es la técnica manual artística de representación sino el ojo que enfoca la escena con el objetivo (Benjamin, 2012: 12).

Para comprender en su totalidad el significado de esta imagen habría que tener en cuenta tanto la perspectiva del fotógrafo -con su ideología y sus intenciones- como la de los posibles espectadores -con sus propias experiencias e ideas-. No se puede olvidar que fotografiar es un intento de contar un relato a través de la imagen en la que se mezclan emociones y sentimientos. ¿Qué sintieron los espectadores de esta misa en Dos Hermanas? Probablemente estaban tan inmersos en un proceso de politización muy profundo y tan impresionados por lo que estaban viviendo que normalizaban la situación. Además, serían más o menos personas próximas a ese entorno político ya que no cualquiera podría acceder a un cuartel de tropas italianas en pleno período de guerra activa y conocerían la decoración. Por ello, es probable que no les sorprendiese la imagen, dado el sesgo de unión entre iglesia y poder político-militar que estaba apareciendo en España en esos momentos. Diferente es lo que esta imagen provoca a un espectador actual. Lo primero, sorpresa ante esa fusión iconográfica entre fascismo y acto religioso y lo segundo, tal vez, incredulidad e incertidumbre.

\section{Notas}

1 Agradezco a la familia de D. José María Gómez Sánchez la autorización para utilizar estas fotografías en el presente artículo.

\section{Bibliografía}

BENJAMIN, Walter (2012), La obra de arte en la época de su reproducción mecánica, Casimiro Libros, Madrid. GÓMEZ SÁNCHEZ, José María (2014), El Paraíso abatido, Ediciones Gráficas Nazarenas, Dos Hermanas (Sevilla). HIDALGO PANIAGUA, David (2014), «Italianos en Dos Hermanas: les llamó la guerra, les venció el amor», Revista de Feria de Dos Hermanas, pp. 95-101.

RIGHETTI, Mario (1955), Historia de la Liturgia, tomo I, Biblioteca de Autores Cristianos, Madrid.

TOUCHARD, Jean (1985), Historia de las ideas políticas, Tecnos, Madrid.

VERDÚ, Daniel (2020), «Entrevista Antonio Scurati», El País Semanal, n. ${ }^{\circ} 2258,5$ de enero, p. 47. 